AsCLePIO. Revista de Historia de la Medicina y de la Ciencia

66 (2), julio-diciembre 2014, p063

ISSN-L:0210-4466

http://dx.doi.org/10.3989/asclepio.2014.27

\title{
ANARCOSINDICALISMO Y SANIDAD EN LA RETAGUARDIA Y EN EL FRENTE. LOS CASOS DE VALENCIA Y DE LA COLUMNA DE HIERRO EN LA GUERRA CIVIL ESPAÑOLA (1936-1937)
}

\author{
Xavier García Ferrandis \\ Universidad Católica de Valencia «San Vicente Mártir» \\ xavier.garcia@ucv.es
}

Recibido: 16 diciembre 2013; Aceptado: 22 mayo 2014.

Cómo citar este artículo/Citation: García Ferrandis, Xavier (2014), "Anarcosindicalismo y sanidad en la retaguardia y en el frente. Los casos de Valencia y de la Columna de Hierro en la Guerra Civil española (1936-1937)", Asclepio, 66 (2): p063. http://dx.doi. org/10.3989/asclepio.2014.27

RESUMEN: El principal nexo de unión entre el anarquismo y la Guerra Civil española es la revolución que surgió del fracaso de la insurrección militar. Como es conocido, el aspecto socioeconómico de esta revolución ha sido ampliamente abordado; sin embargo, el impacto de la revolución anarquista en el terreno sanitario ha sido estudiado parcialmente. El objetivo general de este artículo es analizar la relación que se estableció entre el anarquismo y la política sanitaria en el contexto de la revolución social que se vivió en algunas zonas de la España republicana durante, aproximadamente, el primer año de conflicto. En concreto, el trabajo se centra en Valencia, una ciudad imprescindible en este tipo de estudios por su enorme importancia geopolítica y geoestratégica durante el período de análisis. Además, se aborda el análisis de la organización sanitaria de la Columna de Hierro, la milicia anarquista por excelencia que operó en el frente de Teruel. En Valencia, el anarquismo aplicó prácticas revolucionarias al ámbito de la salud con el objetivo final de conseguir la colectivización de la asistencia sanitaria. Posteriormente, el transcurso de los acontecimientos políticos en la España leal apartó progresivamente al anarquismo de la política sanitaria de la ciudad.

PALABRAS CLAVE: Anarquismo; Sanidad; Guerra Civil española; Valencia; Columna de Hierro.

ANARCHO-SYNDICALISM AND HEALTHCARE IN THE REARGUARD AND IN THE WAR FRONT. THE CASES OF VALENCIA AND THE COLUMNA DE HIERRO IN THE SPANISH CIVIL WAR (1936-1937)

ABSTRACT: Revolution that emerged from the failure of the military insurrection is the main link between anarchism and the Spanish Civil War. As known, the socio-economic aspect of this revolution has been widely discussed, but the impact of the anarchist revolution in healthcare has been studied partially. The overall aim of this article is to analyze the relationship established between anarchism and health policy in the context of the social revolution that took place in some parts of Republican Spain for about the first year of conflict. Healthcare organization of the Columna de Hierro, the most famous anarchist militia that operated in the Teruel front, is also approached. In Valencia, anarchism implemented revolutionary practices in the healthcare field in order to get the collectivization of medical care. Subsequently, the course of political events in loyal Spain progressively keep anarchism away from health policy.

KEY WORDS: Anarchism; Healthcare; Spanish Civil War; Valencia; Columna de Hierro.

Copyright: ( $) 2014$ CSIC. Este es un artículo de acceso abierto distribuido bajo los términos de la licencia Creative Commons Attribution-Non Commercial (by-nc) Spain 3.0. 


\section{INTRODUCCIÓN}

La historiografía del anarquismo durante la Guerra Civil española requiere de un salto cualitativo que solo se ha producido en algunos estudios locales. Seguir en esa dirección puede ser una de las formas más eficaces para seguir abordando la evaluación de la revolución social que se produjo en algunos lugares de la España republicana (Cattini, Santacana, 2002, p. 218). Siguiendo esta recomendación, el objetivo general de este artículo es determinar en qué medida la actividad revolucionaria que el anarcosindicalismo desplegó durante los primeros meses de la Guerra Civil afectó al ámbito sanitario; en concreto, analizaremos en profundidad el caso de Valencia, una ciudad donde confluyeron varios factores que hacen especialmente atractivo el estudio del binomio anarquismo-sanidad: el gran arraigo del anarcosindicalismo durante los años 30 del siglo pasado; el fracaso del golpe de Estado del 18 de julio de 1936; la gran importancia geopolítica, ya que la ciudad albergó la capitalidad del Estado republicano durante casi un año; y la gran importancia geoestratégica, es decir, la posición de retaguardia durante la totalidad de la conflagración, que hizo que una de las prioridades más inmediatas de la ciudad tras el estallido de guerra fuera la respuesta sanitaria al nuevo contexto, con el fin de aumentar la oferta sanitaria para poder atender a heridos y enfermos de guerra y a refugiados.

Los efectos negativos de la revolución industrial y del capitalismo en la salud de los trabajadores han sido considerados como la justificación de la tradicional presencia de médicos en los movimientos anarquistas europeos (Martí Boscà, 2010, p. 52). Sin embargo, en la España del primer tercio del siglo XX, los profesionales de la sanidad no estaban mejor considerados que el resto de técnicos o intelectuales que compartían principios anarquistas, siendo la presencia de médicos en la CNT muy poco significativa durante aquel período (Molero-Mesa, Jiménez-Lucena, 2013, pp. 26-27).

Durante la República, el movimiento anarquista desarrolló una importante desconfianza hacia los profesionales sanitarios porque consideraba que tenían mentalidad burguesa y ejercían su profesión con fines mercantilistas, lo que suponía la explotación de los enfermos y dificultaba la emancipación de la clase obrera (Jiménez-Lucena, Molero-Mesa, 2003, p. 214; Jiménez-Lucena, 2004, p. 144, 145, 147). Por este motivo, algunos médicos anarquistas como Isaac Puente consideraban que la revolución social tenía que hacerse sin contar con los intelectuales ni con los técnicos (Jiménez-Lucena, 1998, p. 306); sin embargo, desde principio del siglo XX el seno de la CNT albergaba un complejo debate sobre las dinámicas de inclusiónexclusión de los «técnicos» o «intelectuales» (médi- cos, enfermeras y practicantes en nuestro caso) en las filas del sindicato (Molero-Mesa, Jiménez-Lucena, 2013). La carencia de intelectuales en el movimiento anarquista español resultaba llamativa en 1936; el anarquismo consideraba que el intelectual era necesario como soporte ideológico de la revolución y, en el caso de los profesionales sanitarios, se solicitaba su implicación en la situación social y la disposición de sus conocimientos al servicio de quienes más lo necesitaba. Por todo ello, al principio de la Guerra Civil la CNT facilitó la integración de intelectuales rebajando al mínimo las exigencias de ingreso, lo que supuso un notable aumento de médicos afiliados a la CNT con las consiguientes críticas de las Juventudes Libertarias (Fernández Soria, 1996, pp. 189-205).

El anarcosindicalismo español mostró un gran interés por los servicios sanitarios en periodos inmediatamente anteriores a la etapa bélica de la Segunda República, lo que explica el protagonismo que adquirió la sanidad en el seno de la CNT durante el primer año de guerra. Efectivamente, durante el periodo republicano la prensa anarquista denunció constantemente una serie de problemas que afectaban a la salud y a la sanidad de la clase obrera. Entre estos problemas destacamos los fraudes cometidos por las mutuas en relación con los accidentes laborales y la presencia de personal religioso en los centros hospitalarios, que daba lugar a casos de discriminación en pacientes que no profesaban la religión católica (Jiménez-Lucena, Molero-Mesa, 2003, pp. 211-215; Jiménez-Lucena, 2004, pp. 146-147). Por otra parte, en el seno de la sanidad libertaria durante la Segunda República existieron otros muchos temas de debate que produjeron tensiones entre las distintas corrientes del pensamiento anarquista: el naturismo, el neomaltusianismo, el control de la natalidad y el aborto, entre otros. Así, Isaac Puente reconocía el derecho de la mujer a abortar por decisión materna y se mostraba partidario del aborto terapéutico (Fernández de Mendiola, 2007, p. 222). Estos supuestos serían recogidos con posterioridad a la muerte de Puente en la legislación propiciada por Félix Martí Ibáñez (Hervàs, 2004, p. 153). Por el contrario, la línea editorial de la publicación anarquista La Revista Blanca se mostraba claramente contraria al aborto. Este grupo estaba formado por Juan Montseny y Teresa Mané (padres de Federica Montseny que firmaban con los pseudónimos Federico Urales y Soledad Gustavo respectivamente, como es conocido), la propia Federica Montseny, Germinal Esgleas, Ángel Fernández, Rafael Doménech y Onofre Dallas (Arriaga et al., 2007, pp. 23, 28-29). El control de la natalidad fue otro de los temas de debate entre los médicos anarquistas. Una corriente mantenía que el exceso de hijos en las familias trabajadoras suponía miseria y enfermedad, mientras que otra línea de pensamiento consideraba que la disminución del número de trabajadores podía retrasar la revolución 
(Martí Boscà, 2006, pp. 70, 72, 74). Respecto de la medicina naturista, las investigaciones realizadas hasta la fecha parecen indicar que lo que caracterizaba a los médicos libertarios era su diversidad terapéutica. Algunos como Isaac Puente y Javier Serrano la practicaron de manera moderada, sin oponerla a la medicina académica sino frente a los excesos terapéuticos, que consideraban mercantilistas y clasistas.

No es nuestro objetivo analizar la política sanitaria del Ministerio de Sanidad y Asistencia Social, creado en noviembre de 1936 y encabezado por la anarquista Federica Montseny ${ }^{1}$, como es conocido. Tampoco deseamos abordar las relaciones entre el ministerio anarquista y la $\mathrm{CNT}^{2}$. Pretendemos más bien determinar en qué medida el anarquismo valenciano de base resolvió algunos de los problemas sanitarios que, según el anarquismo español en general, afectaban a la clase trabajadora durante la Segunda República y que los sucesivos gobiernos fueron incapaces de reconducir. Asimismo, deseamos conocer la dinámica que se adoptó en el caso valenciano en cuanto a la estrategia de inclusión-exclusión de los profesionales sanitarios en las filas anarcosindicalistas, un debate que adquirió gran trascendencia durante el periodo republicano (Molero-Mesa, Jiménez-Lucena, 2013; TaberneroHolgado, Jiménez-Lucena, Molero-Mesa, 2013). Además, nuestro objetivo es establecer si los anarquistas valencianos construyeron una red sanitaria y llevaron a cabo la colectivización de la asistencia sanitaria previa incautación de los recursos privados existentes, aspectos claves dentro del ámbito sanitario para el anarquismo español durante los primeros meses de guerra (Jiménez-Lucena, 2004, p. 158). Finalmente, nuestra investigación pretende dilucidar si las diferencias entre las concepciones sanitarias de anarquistas, socialistas (PSOE, UGT) y comunistas (PCE) que se manifestaron durante la Segunda República continuaron durante el periodo bélico en el ámbito valenciano. Conviene señalar que bajo el término "anarquistas» y "anarquismo" hemos incluido a militantes de la CNT y de la FAl. Como es sabido, la FAI fue fundada en 1927 por miembros de la CNT con el objetivo de extender los principios anarquistas a la sociedad y hacer frente a cualquier postura reformista que intentara convertir la CNT en un sindicato tradicional. Desde el 21 de julio de 1936, la tendencia general fue que ambas organizaciones se fundieran en una única entidad conocida como CNT-FAl (Stuart, 2010, pp. 43, 47, 49, 50, 197). En general, durante los primeros meses de la guerra la CNT tuvo mayor protagonismo en la organización sanitaria; en paralelo, la FAl también desarrolló algunas iniciativas sanitarias, aunque de manera más bien aislada. En el caso valenciano resultan paradigmáticos los hospitales de sangre de la Columna Iberia (García Ferrandis, 2014a, pp. 11-12) y de la Gran Vía Germanías, ambos creados por la $\mathrm{FAl}^{3}$.
En primer lugar analizaremos los servicios sanitarios organizados por la Confederación Nacional del Trabajo en Valencia en respuesta al estallido y posterior desarrollo de la Guerra Civil. Posteriormente centraremos el análisis en la organización sanitaria de la Columna de Hierro para realizar una aproximación a diferentes aspectos de la milicia anarquista (organización, efectividad, disciplina, etc.) a través del análisis de documentación sanitaria ${ }^{4}$. Para alcanzar los objetivos del trabajo hemos consultado el diario Fragua Social, órgano de expresión de los anarquistas valencianos que recoge aspectos fundamentales relacionados con la sanidad durante el período de estudio, como los problemas sanitarios de la clase obrera valenciana y sus soluciones por parte de la CNT. Asimismo hemos analizado fondos documentales del Archivo de la Diputación de Valencia que nos han permitido conocer las actividades desarrolladas por la CNT relacionadas con la asistencia sanitaria: actas de incautación, reflexiones acerca del comportamiento de los profesionales sanitarios, nombramientos, gestión de hospitales, etc.

El periodo histórico en el que nos hemos centrado es la etapa revolucionaria de la Guerra Civil española, período inicial de la contienda caracterizado por una hegemonía política de los sindicatos (muy especialmente de la CNT). Como es conocido, el punto de inflexión que marcó la anulación política de los anarquistas fueron los sucesos acaecidos en Barcelona en mayo de 1937; pese a este denominador común, resulta complicado acotar con exactitud el límite posterior de la etapa revolucionaria, ya que la recomposición del Estado republicano fue progresiva y desigual según la zona de la España republicana. Nosotros hemos situado la pérdida de influencia de la CNT en el ámbito sanitario valenciano a finales de septiembre de 1937, por motivos que expondremos posteriormente. Asimismo hemos especificado la cristalización de este alejamiento de los anarquistas valencianos respecto de la política sanitaria, retomando, así pues, la recomendación de algunos investigadores que consideran que el período que comienza en mayo-junio de 1937, con el fracaso definitivo de la apuesta gubernamental y la pérdida de influencia de la CNT, sigue siendo otra de las asignaturas pendientes (Cattini, Santacana, 2002, p. 219).

Por otra parte, durante la etapa prebélica de la Segunda República se manifestaron una serie de diferencias entre anarquistas, socialistas y comunistas debido a concepciones divergentes de la política sanitaria. Así, mientras la UGT confiaba a los médicos sus políticas sanitarias, los sindicatos anarquistas consideraban que el «intelectual» no era el más indicado para tomar decisiones que afectaban a la masa obrera (Jiménez-Lucena, 1998, pp. 303, 306-307). Además, el igualitarismo asistencial defendido en el ámbito anarcosindicalista generó una creciente resistencia al 
modelo de seguros sociales sanitarios proyectado por el Gobierno y aceptado por la corriente socialista del movimiento obrero (Jiménez-Lucena, 2004, p. 154). En último lugar, hay que señalar que desde comienzos del siglo XX se había establecido entre la UGT y la CNT un debate acerca de qué la estrategia a seguir para solucionar el impacto del capitalismo en la salud de la clase trabajadora. La UGT apostó por el «sindicalismo a base múltiple» y abogó por la creación de sociedades de socorros mutuos, mientras que la CNT desde su fundación optó por la "acción directa». Pese a ser esta la postura oficial, durante los años 30 en el seno de la CNT se articuló un debate en torno a qué estrategia seguir: el sector sindicalista o reformista encabezado por Ángel Pestaña ignoró la acción directa y propuso la creación de mutuas obreras para evitar la explotación de las mutuas sanitarias y las deficiencias del sistema de beneficencia. Para el sector reformista, la mala calidad de la asistencia sanitaria del proletariado requería una solución urgente, que no podía esperar a la revolución social. Por el contrario, los médicos cercanos a la FAI -encabezados por Isaac Puente- establecían la revolución social como único mecanismo para luchar contra el paro, las condiciones de la vivienda, las condiciones laborales, la carestía de la vida..., origen, según esta corriente de pensamiento, de las enfermedades que afectaban a la clase trabajadora (Molero Mesa, Jiménez-Lucena, Tabernero Holgado, 2013, pp. 1-6). Como es sabido, este tema de debate no fue menor y llegó a influir en la escisión de la CNT durante la República. Por su parte, los comunistas se mostraron partidarios de la actuación unitaria de los trabajadores en materia sanitaria y promocionaron la puesta en marcha del Socorro Obrero Español, un organismo destinado a recaudar fondos para esa cuestión (Jiménez-Lucena, 1998, p. 305).

Como es conocido, la insurrección militar del 18 de julio de 1936 supuso la descomposición del Estado republicano en las ciudades y pueblos donde no triunfó 5 . Ante este vacío de poder los sindicatos CNT y UGT y, en menor medida, los partidos del Frente Popular se encargaron de reconducir la situación para hacer frente a los militares sublevados. Desde el punto de vista político, esta respuesta dio origen a los comités ejecutivos populares, organismos revolucionarios que entre julio de 1936 y principios de 1937 ejercieron todas las competencias a través de varias delegaciones. Desde Valencia el Gobierno de Largo Caballero inició un progresivo proceso de centralización política que supuso una pérdida de poder de los sindicatos a favor de los partidos políticos partidarios de un gobierno fuerte, muy especialmente el PCE. Esta maniobra supuso la asimilación de los comités revolucionarios mediante la creación de los consejos provinciales, unos organismos con las competencias recortadas ${ }^{6}$.
Durante la Guerra Civil continuó la polémica a propósito de la política sanitaria republicana debido a las diferentes orientaciones de anarquistas, socialistas y comunistas, diferencias que conviene enmarcar en una concepción igualmente opuesta ante la dicotomía guerra o revolución. Como es sabido, el Gobierno consideraba que el mando único era imprescindible para ganar la guerra, objetivo fundamental. Los socialistas, los comunistas del PCE y los republicanos se mostraron partidarios de esta opción. Enfrente se situaron los comunistas del POUM y los anarquistas, partidarios de hacer la guerra y la revolución al mismo tiempo.

En este contexto, en noviembre de 1936 se produjeron una serie de consideraciones críticas del médico valenciano José Estellés Salarich (1896-1990) hacia la ministra anarquista Federica Montseny. Cuando estalló la Guerra Civil Estellés ocupaba la Secretaría General Técnica de la Dirección General de Sanidad y la Secretaría General de la Federación de Sindicatos Médicos de la UGT. En enero de 1937 fue nombrado con carácter interino Inspector General de Sanidad. En relación con la Sanidad militar, Estellés criticó la excesiva proliferación de hospitales para convalecientes por la dispersión de recursos humanos y materiales que conllevaba. Además, reivindicó la necesidad de coordinar los servicios sanitarios militares y civiles, pero sin perder de vista que una vez superado el paréntesis bélico la sanidad civil debía readaptarse a la vida civil ordinaria. Por otra parte, el médico valenciano criticaba abiertamente la estructura organizativa del ministerio dirigido por Montseny al referirse a una "Sanidad ministerial» donde había proliferado una numerosa y abundante burocracia sindical que diluía la responsabilidad del personal disminuyendo así la eficacia (Bernabeu-Mestre, 2007, p. 91-102).

Respecto de la sanidad republicana en la Guerra Civil, hay que señalar que durante las primeras semanas de conflicto la descomposición del Cuerpo de Sanidad Militar obligó a la sanidad civil a reorganizarse con el objetivo de suplirlo. Esta adaptación no estuvo exenta, sin embargo, de algunos problemas derivados de la falta de experiencia en el ámbito militar, como por ejemplo el exceso de oferta sanitaria y consiguiente dispersión de recursos médicos humanos y materiales. Como veremos posteriormente, la CNT participó en esta primera etapa de la sanidad de guerra con la creación de varios hospitales de capacidad limitada, aunque posteriormente hizo una advertencia sobre "la [excesiva] oferta de hospitales de sangre y la de lugares de convalecencia [que] cubre con exceso la demanda ${ }^{7}$. Más tarde, en el marco de centralización política impulsada por Largo Caballero, se dispuso la militarización de los hospitales con una capacidad superior a las 300 camas y el cierre de los de una capacidad inferior ${ }^{8}$, medida que facilitó la reorganización de una auténtica Sanidad Militar a partir de $1937^{9}$. 


\section{DE LA REVOLUCIÓN SANITARIA ANARQUISTA A LA PÉRDIDA DE INFLUENCIA DE LA CNT}

Antes de centrarnos en el caso valenciano hemos de referirnos a Barcelona por dos motivos. En primer lugar, porque se trata del paradigma urbano por excelencia de guerra, revolución y anarquismo. Además, las similitudes con Valencia resultan evidentes, como tendremos ocasión de comprobar. Durante las primeras semanas de guerra en Barcelona proliferaron abundantes hospitales, cinco de los cuales fueron creados (tres de ellos en edificios incautados) y gestionados por la CNT. A partir de octubre de 1936 la CNT se integró en el Gobierno de la Generalitat y tuvo gran influencia en la política sanitaria. De hecho, hasta junio de 1937 la Conselleria de Sanitat estuvo ocupada por cuatro miembros del sindicato anarquista. Esta continuidad permitió a los anarquistas catalanes Ilevar a la práctica una política sanitaria libertaria, cuyo ideológo fue Félix Martí Ibañez, médico anarquista y director general de Sanidad hasta el 1 de julio de 1937. Esta política sanitaria se articuló alrededor de la colectivización de la medicina y la regulación del aborto, aunque quedó interrumpida tras la salidad del la CNT del Govern como consecuencia de los sucesos de Barcelona de mayo de 1937 (Hervàs, 2004, pp. 64, 83, 103, 105 y siguientes, 170).

Como en el caso catalán, en Valencia a lo largo de las primeras semanas de guerra se habilitó toda una red de instalaciones sanitarias que, junto con otras ya existentes de carácter civil readaptadas a la nueva situación, se englobaron bajo el nombre de hospitales de sangre ${ }^{10}$. La importancia del ámbito sanitario en Valencia queda reflejada en la rápida constitución del Comité Sanitario Popular, una delegación del Comité Ejecutivo. El Comité Sanitario Popular estaba dividido a su vez en varias delegaciones, entre las que destacaba por su poder y competencias el Departamento de Hospitales y Sanatorios, dirigido por Emilio Navarro Beltrán, médico libertario afiliado a la CNT. Así las cosas, resulta evidente que durante la etapa revolucionaria de la guerra el sindicato anarquista adquirió un gran protagonismo en la gestión de la sanidad valenciana que se tradujo en numerosas iniciativas y acciones. En primer lugar, uno de los puntos de máximo interés para la CNT en Valencia fue la gestión de los accidentes de trabajo, para lo que el 29 de agosto de 1936 se procedió a la incautación de todas las compañías de seguros de la ciudad y provincia. Según la CNT, la incautación era la solución a la dificultad en la aplicación de estas prestaciones sanitarias a causa de la pugna de intereses entre los beneficiarios y los gestores del seguro, por lo que la solución era que los trabajadores fueran receptores y administradores ${ }^{11}$. En este contexto, la CNT habilitó en Valencia dos policlínicas de accidentes de trabajo en sendos edificios previamente incautados: el Asilo de Santa Filomena, propiedad de la orden religiosa del Calvario ${ }^{12}$, y en la vivienda y clínica particular de un médico de la ciudad $^{13}$. Respecto de la estrategia de inclusión-exclusión de los profesionales sanitarios en la revolución, se abrió un debate hasta llegar a la conclusión de que para los trabajadores el $95 \%$ de los médicos eran «indomables reaccionarios». Pese a ello, la CNT valenciana descartaba la depuración en masa y abogaba por la incorporación progresiva de la "clase médica» a la revolución porque «¿quiénes van a ocupar las plazas de los que consideremos desafectos al régimen?» Por este motivo la CNT recomendaba atraer a las clases intelectuales mediante el debate de ideas en diferentes foros, aunque puntualizaba: "Cuando aquella [la guerra] termine será el momento de hacer la sustitución (...). Ellos ya lo saben y nosotros también: el que no se adapta al medio, y el medio es la revolución, desaparece ${ }^{14}$. Por otra parte, la CNT impulsó la creación de una «Delegación Sanitaria Regional del País Valenciano», cuyo objetivo era coordinar los servicios sanitarios de las tres provincias valencianas sin menoscabar la autonomía de los respectivos comités sanitarios populares ${ }^{15}$. Asimismo, la CNT a través del Comité Sanitario se dirigió a los diferentes distritos provinciales para conocer los datos de morbimortalidad en los pueblos de la provincia de Valencia por tuberculosis, paludismo, tifus, difteria y raquitismo, y para conocer la calidad de las aguas de consumo y el funcionamiento del alcantarillado ${ }^{16}$.

Otro de los objetivos de la CNT durante la etapa revolucionaria de la guerra fue la asistencia sanitaria universal y gratuita. En el caso de Valencia resulta paradigmática la colectivización de la cobertura odontológica. Así, el 18 de septiembre de 1936, la Federación Nacional de protésicos dentales (UGT-CNT) impulsó ante el Comité Sanitario la creación de cinco equipos odontológicos formados por material incautado en las tiendas de Valencia. En noviembre de ese año el Sindicato Ferroviario (CNT) cedió dos clínicas odontológicas incautadas al principio de la guerra para instalar una policlínica dental que prestara asistencia gratuita a los refugiados y a los autóctonos sin recursos ${ }^{17}$. Además de las incautaciones, la CNT impulsó ante el Comité Sanitario el gravamen de las transacciones de especialidades farmacéuticas y materiales de cura, cuyo importe «se destina a cubrir la atención sanitaria de enfermos parados o necesitados ${ }^{18}$. En definitiva, el objetivo final de la política sanitaria anarquista era garantizar la asistencia sanitaria universal y gratuita, para lo que la CNT llevó a cabo numerosas incautaciones porque consideraba que para gestionar la sanidad era necesario poseer y administrar determinadas instalaciones sanitarias.

Siguiendo las líneas maestras de su política en el campo de la sanidad (asistencia sanitaria gratuita y universal, incautaciones e inclusión de los profesiona- 
les sanitarios), la CNT organizó una serie de instalaciones sanitarias en la ciudad de Valencia durante las primeras semanas de la guerra. Para gestionar, coordinar y controlar todas estas infraestructuras, la CNT creó el "Control Sanitario», un organismo con poder de fiscalización que tenía las siguientes atribuciones: controlar la afiliación de los profesionales sanitarios que trabajaban en las hospitales de la CNT, proveer de material médico y comestibles a las diferentes clínicas, centralizar los ingresos y las altas de enfermos y heridos y, asimismo, llevar los libros de contabilidad de los diferentes centros sanitarios. Los responsables del Control Sanitario eran un médico delegado de la CNT (el mismo Navarro Beltrán), un delegado local y un ingeniero técnico asesor. Las actividades del Control se financiaban mediante suscripción popular y los beneficios obtenidos de un taller mecánico atendido por afiliados ${ }^{19}$. En la figura 1 puede observarse que el Control Sanitario estaba situado en el número 57 de la calle Guillem de Castro, localización estratégica por estar muy cerca del Hospital Provincial.

El primer hospital de sangre que instaló la CNT fue precisamente en el local del Control Sanitario. La plantilla de este hospital estaba formada por cinco médicos, dos radiólogos, tres practicantes, dos enfermeros y cuatro enfermeras, y la dirección facultativa estaba en manos de José Lanuza Bonilla. Con una capacidad de 25 camas, este hospital disponía de servicio de radiología y un quirófano ${ }^{20}$, y en él se atendían básicamente a los milicianos heridos o enfermos de la Columna de Hierro ${ }^{21}$. Además, el hospital disponía de una posta sanitaria de urgencia atendida por el mismo personal sanitario que funcionaba desde el 21 de julio ${ }^{22}$. La fecha en que entró en funcionamiento esta posta nos permite afirmar que la respuesta en materia sanitaria de la CNT a la violencia tras el golpe militar del día 18 fue muy rápida. Además de las formas de financiación referidas anteriormente, uno de los radiólogos que trabajaba en este hospital de sangre había puesto a disposición del mismo el material de su propiedad ${ }^{23}$. Esta forma de autofinanciación recuerda los métodos de la Organización Sanitaria Obrera de la Barcelona republicana (Jiménez-Lucena; Molero Mesa, 2003, p. 217). Es decir, las experiencias anarquistas en el ámbito sanitario durante la República fueron de gran interés durante el periodo bélico.

A partir de octubre de 1936, una vez consolidado el conflicto bélico, el Control Sanitario de la CNT de Valencia anunció a través de Fragua Social un proyecto más ambicioso: la instalación en la ciudad de 12 clínicas destinadas a la atención de diferentes especialidades medicoquirúrgicas ${ }^{24}$. Una de estas clínicas era la Casa de Maternidad que se instaló en una casa señorial incautada situada en las afueras de la ciudad (Chalet de Ayora). En este hospital prestaba sus servicios un tocólogo $0^{25}$ y una comadrona y tenía como objetivo acoger a "40 compañeras que serán atendidas más humanamente que lo eran en otros centros donde se atendía más que nada el catolicismo que el malestar de la paciente ${ }^{26}$. Aunque también estaba organizado y gestionado por la CNT, los gastos de la maternidad corrían a cargo del Hospital Provincial. Así lo demuestran una serie de facturas de gasolina, electricidad y obras de acondicionamiento datadas entre el 20 de mayo y el 30 de julio de 1937 que hemos encontrado entre la documentación consultada ${ }^{27}$. Durante los tres primeros meses de 1937 se atendieron de forma gratuita a más de 90 mujeres que el Hospital Provincial no había podido atender por falta de espacio ${ }^{28}$. Resulta evidente, por tanto, que con la instalación de este

Figura 1. Control Sanitario de la CNT. Fuente: D.6.1 caja 14. Hospitales. A.D.P.V.

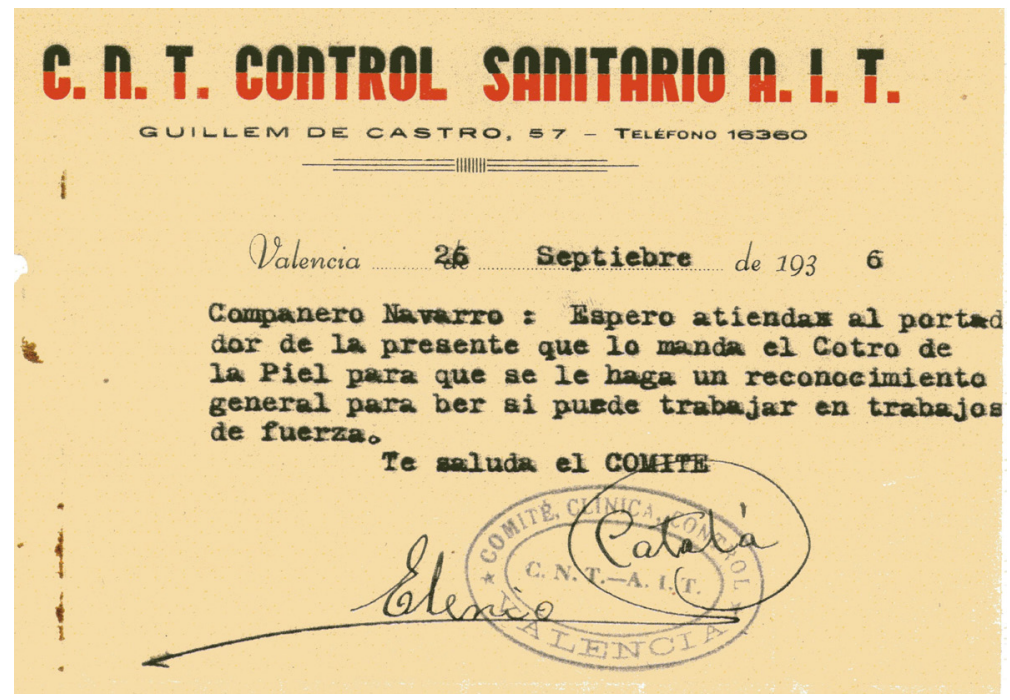


hospital, la CNT descentralizó el servicio de maternidad del Hospital Provincial en un intento de impedir el colapso del mismo. En la figura 2 se puede apreciar el sello de la Casa de Maternidad.

La administración de la Casa de Maternidad resulta paradigmática de la doble faceta de los anarcosindicalistas en su actuación sanitaria, a través de los órganos de gobierno y desde su propia organización sindical. Así, este centro sanitario estaba gestionado por la CNT como fuerza sindical (de ahí que estuviera bajo dependencia del Control Sanitario de la CNT), pero los gastos eran sufragados por el Hospital Provincial, es decir, por la CNT a través de los órganos de gobierno, ya que como comprobaremos este hospital estuvo bajo control del sindicato hasta marzo de 1937. Esta participación de la CNT en la política sanitaria desde los órganos de gobierno no planteó ningún problema con la máxima autoridad revolucionaria en materia sanitaria: el Comité Sanitario Popular. Esta sintonía es fácilmente entendible si tenemos en cuenta la composición del Comité Ejecutivo Popular de Valencia: la CNT pasó a controlar las delegaciones de Propaganda y Transportes, mientras que la Delegación de Sanidad fue asumida por Francisco Bosch Morata, del Partit Valencianista d'Esquerra; pese a esta distribución, el poderoso Departamento de Hospitales y Sanatorios del Comité Sanitario Popular estaba dirigido, como sabemos, por Emilio Navarro Beltrán. Desde el punto de vista de la organización sindical, la CNT tampoco tuvo dificultad alguna porque, como hemos señalado, el médico delegado del Control Sanitario era el mismo Navarro Beltrán.

Siguiendo con las instalaciones sanitarias, la CNT contaba con otro hospital de sangre en el número 36 de la Gran Vía Germanías, instalado en un sanatorio propiedad de un médico derechista ${ }^{29}$. A pesar de la ideología del médico parece ser que nunca hubo ningún problema entre los milicianos y el médico (Amorós, 2009, pp. 128-129). De hecho, el antiguo propietario continuó como médico director y contó con la ayuda de un cirujano anarquista. El sanatorio había sido incautado y transformado en hospital de sangre por la FAI y, posteriormente, fue cedido a la Columna de Hierro para la atención médica de sus miembros (Amorós, 2009, p. 128). En la figura 3 se puede apreciar un oficio relacionado con este hospital de sangre.

Figura 2. Hospital de Maternidad de la CNT. Fuente: D.6.1 caja 12. Maternidad. A.D.P.V.

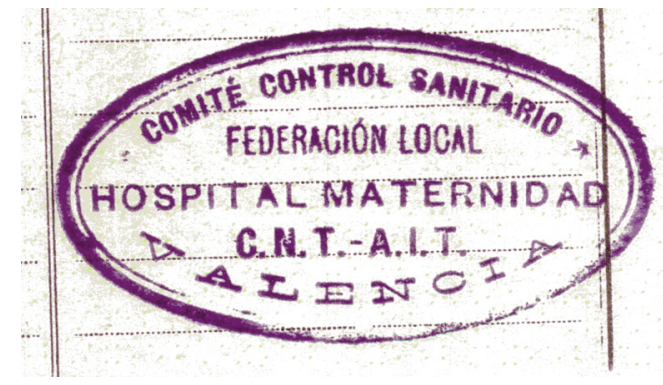

Figura 3. Hospital de Sangre de la CNT. Fuente: D.6.1 caja 14. Hospitales. A.D.P.V.

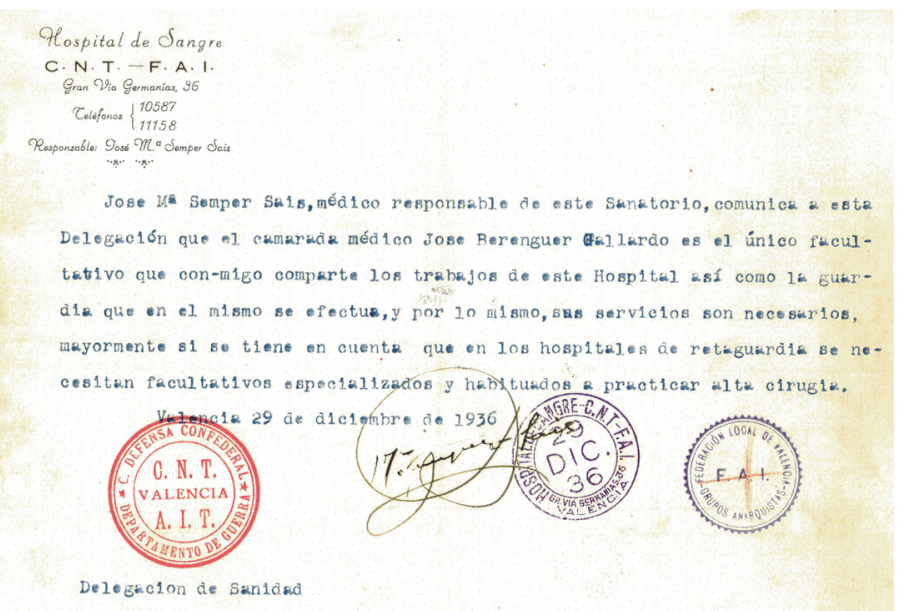


En último lugar, la CNT disponía del Sanatorio Villa María. Situado entre los números 53 y 55 del Camino del Grao (actual Avenida del Puerto), este centro sanitario fue incautado a su propietario y director el 20 de julio de 1936. En diciembre de ese año fue transformado en hospital de sangre por «necesidades de guerra»; disponía de 16 camas, estaba equipado con una mesa de operaciones, abundante material quirúrgico y material anestésico y contaba con «adelantos en la cirugía actual, personal competente médico y enfermeras tituladas ${ }^{30}$.

Otra de las clínicas que la CNT gestionó en Valencia durante la Guerra Civil fue la Mutua Confederal. Se trata de una instalación peculiar puesto que es la única que coordinaba el sindicato con anterioridad al estallido de la guerra. La estrategia anarcosindicalista basada en la acción directa rechazaba que la CNT creara y mantuviera mutuas debido a que esta opción tenía un carácter restrictivo. Este conflicto se dio especialmente en Barcelona donde los partidarios de la acción directa hicieron fracasar el proyecto de la Obra Popular Antituberculosa de Cataluña, y dificultaron las actividades de la Organización Sanitaria Obrera debido a que la CNT no brindó ni el apoyo ni la implicación que los responsables de la mutua le solicitaban (Jiménez-Lucena, Molero-Mesa, 2003; MoleroMesa, Jiménez-Lucena, Tabernero Holgado, 2013). En la Valencia republicana Navarro Beltrán se decantó por el sector reformista y se integró en los Sindicatos de Oposición. En 1931 había organizado la Mutua de Accidentes del Sindicato de Transporte de la CNT en la zona portuaria de Valencia (Martí Boscà, Rey, 2010, p. 65), que pronto se convirtió en la Mutua Confederal, en un modesto intento de dar respuesta a los problemas sanitarios que afectaban al proletariado en relación con las mutuas de accidentes de trabajo. Al principio de la guerra, la CNT hizo propia la iniciativa de Navarro Beltrán e inauguró un nuevo hospital (situado en el barrio del Grao) donde en 1937 llegaron a trabajar 50 médicos "al servicio de los obreros». La Mutua Confederal ofrecía las siguientes prestaciones sanitarias: asistencia médico-quirúrgica a los obreros víctimas de accidentes laborales; seguro de asistencia sanitaria (incluida la hospitalización); y asistencia domiciliaria de urgencia y ambulatoria en policlínica de todas las especialidades médicas y médico-quirúrgicas entonces existentes. Los beneficiarios de estos servicios eran los trabajadores asegurados y sus familias, para lo que el titular abonaba una prima del $2 \%$ de los jornales devengados ${ }^{31}$.

De la información expuesta anteriormente podemos concluir que entre julio y diciembre de 1936 la CNT articuló y gestionó una notable red de infraestructuras sanitarias propias en la ciudad de Valencia. Otra muestra del gran poder de influencia de la CNT en la política sanitaria valenciana durante las primeras semanas de la guerra la encontramos en el Hospital Provincial de Valencia, el más grande del País Valenciano y, por tanto, fundamental para llevar a cabo la reorganización sanitaria durante el conflicto (García Ferrandis, 2012, pp. 364-381; García Ferrandis, 2014b). Será, así pues, en la gestión de este centro hospitalario donde cristalizaran en gran medida las diferentes concepciones en materia sanitaria de los anarquistas y los partidarios del mando único (comunistas y republicanos valencianos). En concreto, en la nueva organización sanitaria revolucionaria la dirección del Hospital Provincial se le encomendó a Emilio Navarro Beltrán, cargo que desempeñó hasta el 16 de diciembre de $1936^{32}$. Navarro Beltrán asumía «la responsabilidad de salvar del caos la asistencia de los pobres menesterosos y heridos de guerra», para lo que consideraba fundamental acometer una serie de reformas en el hospital: «Creímos que lo importante era transformar lo malo de la sociedad burguesa fascista de este Centro Sanitario (...) atendiendo únicamente al cumplimiento estricto de la función benéfico-sanitaria encomendada» ${ }^{33}$. Con este objetivo, la primera medida adoptada fue la expulsión del personal religioso y la sustitución por personal laico. En concreto fueron expulsadas $90 \mathrm{Hijas}$ de la Caridad que a partir de septiembre de 1936 fueron sustituidas por "enfermeras tituladas» ${ }^{34}$. En segundo lugar, la dirección dividió el centro hospitalario en varias secciones técnicas, nombrando un «Delegado Técnico directo» responsable de cada una. Estos delegados, junto con los delegados no técnicos, integraban el Comité Directivo-Administrativo, que era el máximo órgano de gobierno del hospital y estaba integrado por militantes de la CNT y la UGT. Finalmente, los servicios del hospital quedaron articulados en 20 departamentos "civiles» y en cuatro servicios de guerra (tres equipos quirúrgicos y una policlínica de milicianos) $)^{35}$. Pese a esta organización, no faltaron las denuncias formuladas por los enfermos y sus familiares sobre las incapacidades técnicas y el absentismo laboral del personal subalterno afiliado a la $\mathrm{CNT}^{36}$. A la luz de la documentación consultada, cabe pensar que la gestión anarquista del Hospital Provincial para ponerlo al servicio de la revolución supuso un marcado aumento de las estructuras organizativas y una sobrevaloración de la filiación sindical del personal auxiliar en detrimento de la calidad asistencial. Sin embargo, los anarquistas conservaron el origen benéfico y civil del hospital y además fueron capaces de atender las necesidades sanitarias del estado de guerra.

En el contexto de centralización política impulsada por el Gobierno de la República descrito anteriormente, a principios de enero de 1937 quedó constituido el Consejo Provincial de Valencia (que sustituía al revolucionario Comité Ejecutivo Popular). A pesar de que esta reforma tenía como objetivo concentrar el poder en los partidos políticos, la CNT mantuvo ciertas cuotas de poder: la primera vicepresidencia y cinco con- 
sejerías, entre las que se encontraba la Consejería de Sanidad al frente de la cual continuaba el presidente del desaparecido Comité Sanitario Popular, Emilio Navarro Beltrán ${ }^{37}$. No obstante, el 30 de septiembre de 1937 el Gobierno decretó la remodelación de los consejos provinciales ${ }^{38}$, determinando que el Consejo Provincial de Valencia quedara integrado por tres representantes respectivos del PSOE, del PCE y de Izquierda Republicana, por dos miembros de la UGT y por dos representantes de la $\mathrm{CNT}^{39}$. Resulta evidente que los partidos favorables al mando único ganaban influencia política, mientras que los sindicatos de tendencia revolucionaria salían debilitados. La CNT mantenía tan solo dos consejerías y, lo que es más importante para este trabajo, la política sanitaria pasaba a depender de Izquierda Republicana: era la primera vez desde el inicio de la guerra que la sanidad valenciana no era gestionada por la CNT, por lo que la pérdida de influencia del anarquismo en el ámbito sanitario no se hizo esperar. En primer lugar, la nueva Consejería de Sanidad ordenó el traslado del único cirujano del Hospital de Sangre de la CNT de la avenida Germanías, lo que precipitó el cierre del centro sanitario ${ }^{40}$. Respecto del Sanatorio Villa María, el nuevo Consejo Provincial de Valencia no tardó en aplicar la Orden de militarización de los hospitales civiles, una disposición vigente desde enero que, sin embargo, el anterior Consejo no había aplicado. Dada la baja capacidad de este centro sanitario, la aplicación de la Orden supuso su clausu$\mathrm{ra}^{41}$. El acoso a la política sanitaria de la CNT también se manifestó en el Hospital Provincial. Así, el día 17 de diciembre de 1936, la comisaria de guerra Aurora Arnaiz - próxima al PCE - elaboró un informe donde se describían numerosas deficiencias en el trato de los heridos ingresados (falta de ropa, alimentación escasa, condiciones higiénicas deficientes, etc.). El informe atribuía todas estas irregularidades a la falta de organización del Hospital Provincial y concluía apostillando que «no se ha de olvidar que el control de este establecimiento lo lleva la CNT» ${ }^{42}$. Navarro Beltrán se defendió de las acusaciones denunciando la asfixia presupuestaria del Ministerio de la Guerra - dirigido por el socialista Largo Caballero- para la atención de los heridos de guerra. Asimismo, arremetió contra la autora del informe señalando que

podemos demostrar la ineficacia de ciertos elementos sectarios y profanos en la misión de inspectores sanitarios, como la autora de dicha información, que preocupándose de su misión política (...) toman el trágico ambiente y estado psicológico del herido de guerra para manejarlo como banderín de su más o menos acertada ideología ${ }^{43}$.

Finalmente, Navarro Beltrán tuvo que dimitir como director del hospital, aunque fue sustituido por el también médico cenetista José de Lanuza Bonilla (Martí Boscà; Rey González, 2010, p. 66). En enero de 1937 la Consejería de Sanidad volvió a recibir quejas respecto de las deficiencias del Hospital Provincial por parte de los ministros de la Guerra y de Gobernación (este último era el también socialista Ángel Galarza). A finales de marzo del mismo año la Jefatura de los Servicios Sanitarios del Ejército de la República insistió en las deplorables condiciones en que se encontraban los soldados heridos en el recinto hospitalario, lo que finalmente obligó a dimitir a Lanuza Bonilla ${ }^{44}$. Posteriormente, Manuel Alonso (representante de Izquierda Republicana en el Consejo) asumió el cargo de Consejero delegado del Hospital Provincial. Independientemente de la veracidad de las irregularidades denunciadas, esta serie de desencuentros a propósito del funcionamiento del Hospital Provincial debe ser enmarcado en el contexto de las luchas entre anarquistas y partidarios del mando único (comunistas y republicanos valencianos), en este caso centradas en el ámbito sanitario. La siguiente afirmación de un dirigente anónimo de la CNT valenciana corrobora esta idea: "Los mejores [médicos] considerados socialmente los está utilizando la guerra que se los ha robado a la revolución $»^{45}$.

La gestión del Hospital Provincial por Izquierda Republicana tuvo como objetivo principal la colaboración para ganar la guerra. Esto supuso una progresiva militarización del espacio hospitalario favorecida por la Orden del Ministerio de la Guerra de enero de 1937. Por una parte, los equipos quirúrgicos de guerra pasaron de tres a cinco, restando recursos a la sanidad civil $^{46}$. Además, en mayo de 1937 siete practicantes fueron movilizados dejando desatendidos sus puestos en el hospital. Los problemas no se hicieron esperar y, en agosto del mismo año, López Trigo -médico del centro- denunció que había recibido «verdaderos insultos de familiares de enfermas de la Maternidad que no tenían quien les diera ni alimentos ni auxilio alguno ${ }^{47}$. Todo parece indicar, así pues, que la nueva administración del Hospital Provincial no fue capaz de equilibrar eficazmente las funciones militar y civil del centro sanitario, dando prioridad a la primera y desatendiendo a los enfermos civiles.

\section{LOS SERVICIOS SANITARIOS DE LA COLUMNA DE HIERRO}

Durante la etapa revolucionaria, como consecuencia de la desarticulación del Ejército en la España democrática, los sindicatos y partidos políticos asumieron la responsabilidad de organizar las primeras columnas milicianas que partieron hacia los diferentes frentes de guerra establecidos. Posteriormente, en el marco de centralización política impulsado por el Gobierno, se decretó la militarización de las milicias y su integración en las brigadas mixtas del nuevo Ejército Popular de la República ${ }^{48}$. En Valencia se organizaron varias columnas confederales de milicianos que operaron en el cercano frente del Teruel; sin embargo, 
en este apartado nos centraremos en la Columna de Hierro por varios motivos: en primer lugar, porque ha sido considerada como el paradigma de la milicia confederal resistente a la militarización y valedora de los auténticos valores revolucionarios, capaz de hacer la guerra y la revolución a la vez. Además, la composición de la Columna de Hierro (a partir de ahora $\mathrm{CH}$ ) reflejaba los ambientes donde reinaba el anarquismo valenciano: obreros de la construcción, labradores de la huerta, portuarios de Borriana y metalúrgicos de Sagunt (de ahí el nombre), entre otros. La Columna de Torres-Benedito incluía voluntarios de la CNT, pero también de la UGT, del POUM, del Partido Sindicalista y de Esquerra Valenciana, además de soldados procedentes de los diferentes regimientos disueltos en Valencia, por lo que esta unidad miliciana no puede considerarse anarquista en sentido estricto. Las otras dos unidades confederales -Columna Iberia y Columna Temple y Rebeldía - fueron creadas tardíamente (a finales de 1936), apenas participaron en la primera ofensiva sobre Teruel y fueron militarizadas rápidamente (Mainar, 1998, p. 41, 46, 49 y 53).

A principios de agosto de 1936 las primeras unidades de la $\mathrm{CH}$ salieron de Valencia hacia Teruel${ }^{49}$. Tras un primer enfrentamiento en Sarrión, la columna llegó a Puerto Escandón (a escasos kilómetros de Teruel), donde en septiembre de 1936 quedó estabilizado el frente. La CH participó en la primera ofensiva sobre Teruel (invierno 1936-1937) y opuso una gran resistencia a su militarización ya que encuadrarse bajo la disciplina castrense iba en contra de sus principios. De hecho, fue la última columna miliciana que no aceptó la militarización, aunque finalmente tuvo lugar a lo largo de la primavera de 1937 cuando la CH se transformó en la 83 Brigada Mixta y acabó desapareciendo como unidad miliciana. En cuanto a la organización, la columna disponía de varias secciones entre las que se encontraba la de Sanidad (Paz, 2001, p. 212), cuyo delegado era el médico Ramón Sanchis (Amorós, 2009, p. 128). Esta sección desplegó unos potentes servicios sanitarios en el frente de Teruel, que pasamos a analizar a continuación. Los servicios sanitarios de la milicia habilitaron cinco postas sanitarias de urgencia en Puerto Escandón, muy próximas a la primera línea de combate. La evacuación de los heridos atendidos en las postas se llevaba a cabo con mulos y artolas a través de siete kilómetros de sendas de monte, hasta llegar a otra posta sanitaria instalada en una ermita que contaba con una ambulancia cedida por el Instituto de Higiene de Castellón ${ }^{50}$. Las postas estaban atendidas por tres médicos, tres practicantes, cuatro enfermeros y varios camilleros, y disponían de anestésicos (éter, morfina) y material de curas. La evacuación de los heridos se hacía por carretera hasta la localidad de la Puebla de Valverde, donde la $\mathrm{CH}$ disponía de otras tres postas sanitarias atendidas por un total de siete médicos y numerosos practicantes y enfermeros. Estas postas contaban con abundante material quirúrgico (bisturís, estuches de amputación, separador de laparotomía, pinzas sacabalas, etc). La presencia de todo este material y la abundante presencia de médicos en estas postas nos permite afirmar que en ellas se llevaban a cabo actos médicos mucho más complejos que en las postas avanzadas: amputación de miembros y operaciones de heridas en el abdomen. En Puebla de Valverde, además de las tres postas, la $\mathrm{CH}$ había establecido un hospital con capacidad para 50 camas "desde donde se distribuyen los enfermos del frente a los diversos Hospitales [de la retaguardia] ${ }^{51}$. Por tanto, el hospital de Puebla de Valverde estaba concebido como un centro intermedio cuyo objetivo era el control de los pacientes evacuados desde las postas a la espera de su evacuación hacia la retaguardia. En el siguiente mapa pueden observase la distribución de todas las infraestructuras sanitarias analizadas.

A continuación analizaremos los servicios sanitarios de la $\mathrm{CH}$ situados más en retaguardia. En primer lugar, respecto del Hospital de Cedrillas, conviene señalar que estaba controlado y dirigido por la Columna Torres-Benedito, otra de las milicias valencianas que participaron en el asedio de Teruel; sin embargo, en el Hospital de Cedrillas entre el 29 de septiembre de 1936 y el 11 de febrero de 1937 fueron hospitalizados un total de 179 integrantes de la $\mathrm{CH}^{52}$. El análisis de los diagnósticos de estos milicianos aporta una valiosa información sobre determinados aspectos de la columna. Así, hasta el $15 \%$ fueron hospitalizados por enfermedades características del periodo invernal (bronquitis, neumonía, gripe, etc.), frente al $14.5 \%$ que resultaron heridos por causas que podemos atribuir directamente a acciones de guerra, aún a riesgo de ocultar accidentes: heridas por arma de fuego, heridas en sedal y heridas por metralla ${ }^{53}$. En el $10 \%$ de los casos no consta el diagnóstico. El resto fue hospitalizado por enfermedades comunes (sarna, gastritis, sífilis, etc.). Incluso en la ofensiva de la Navidad de 1936 observamos una diferencia significativa entre las bajas de la $\mathrm{CH}$ y las de la 22 Brigada Mixta y la XIII Brigada Internacional. Así, mientras que únicamente ingresaron 11 milicianos (de los que tan solo dos presentaban heridas por arma de fuego), las dos brigadas sumaron un total de 145 bajas, casi todos por heridos de bala y por metralla ${ }^{54}$. Por otra parte, hemos localizado seis diagnósticos que convertía a los milicianos en inútiles para el combate: artrosis, insuficiencia cardiaca y cataratas. Finalmente, cabe destacar que de los 179 miembros de la $\mathrm{CH}$ que ingresaron en el Hospital de Cedrillas tan solo fallecieron cuatro in situ. Los datos que acabamos de exponer se pueden asociar, por una parte, a la improvisación con la que se creó la columna. Solo así se explica la presencia en sus filas de miembros inútiles para el combate y la falta de prendas de abrigo que ocasionó un número considerable 
de bajas. Por otra parte, hemos asociado el discreto porcentaje de heridos de guerra y el número bajo de fallecidos a la estabilidad del frente y, por tanto, a la relativa inacción de la columna. Sin embargo, relacionamos la falta de bajas por heridas por arma de fuego en los días de mayor intensidad bélica, como el 1 de enero de 1937, a la indisciplina de la columna que en ocasiones se negaba a entrar en combate. En este contexto deben situarse los 97 milicianos que desertaron durante la ofensiva sobre Teruel de diciembre de $1936^{55}$.

Cercana a la provincia de Castellón, la localidad de Sarrión albergó a mediados de agosto de 1936 el primer hospital de sangre instalado por la $\mathrm{CH}$. Se instaló en un chalet situado en las afueras de la población ${ }^{56}$ próximo a la carretera y a la estación de ferrocarril y era, por tanto, un buen emplazamiento para un centro sanitario debido a que los hospitales del frente tenían que estar situados cerca de vías rápidas de evacuación (Massons, 1994, p. 443). Hasta el 2 de octubre de 1936 se atendieron en este hospital a 156 heridos de la $\mathrm{CH}$, el $35 \%$ de los cuales presentaban heridas producidas por accidente de coche y manejo inapropiado de armas de fuego ${ }^{57}$. Estos datos pueden enmarcarse en el contexto de inexperiencia y de falta de preparación militar de los milicianos de la $\mathrm{CH}$ al que hemos aludido anteriormente. En la figura 4 se observa el aspecto actual del chalet donde fue instalado el hospital de sangre de Sarrión. Está situado a unos 50 metros de la carretera y a otros tantos de la estación de ferrocarril.
Aunque este hospital fue instalado y gestionado por la CNT y tenía personal sanitario auxiliar propio, solían pasar visita los médicos del tren hospital número 1 , que estaba bajo mando del teniente coronel médico Adolfo Rincón de Arellano Lobo ${ }^{58}$, jefe de los Servicios Sanitarios del frente de Teruel y máximo responsable del Departamento de personal sanitario y suministros de guerra del Comité Sanitario Popular. El tren hospital número 1, cubría el trayecto entre la Estación Central de Aragón (Valencia) y Sarrión, donde tenia la base. Formaba parte de una flota de seis trenes sanitarios que la Sanidad Militar republicana tenía a su disposición (Barona, Bernabeu-Mestre, 2007, p. 106). Cuando iba hacia Segorbe y Valencia tenía la misión de evacuar heridos del Hospital de Sarrión, donde a su vez, habían sido trasladados los heridos de los hospitales de Puebla de Valverde, Mora de Rubielos y Cedrillas ${ }^{59}$. Cuando el tren se dirigía desde Valencia al frente abastecía de material sanitario a las postas y los hospitales. El Hospital de Sarrión disponía de un servicio permanente compuesto por los tres equipos quirúrgicos del tren hospital. Estaba dotado de material de curas y abundante instrumental quirúrgico, tanto como para poder atender cuatro intervenciones a la vez sin necesidad de esterilizar el material utilizado ${ }^{60}$. Esta dotación permitió que en este hospital se llevaran a cabo con éxito intervenciones quirúrgicas de gran envergadura, como una craneotomía en un herido por arma de fuego ${ }^{61}$. El centro sanitario disponía, además, de una sala de rayos $X$ atendida por un radiólogo, un laboratorio y una farmacia correctamente abastecida.

Figura 4. Fuente: el autor a partir del testimonio oral de dos funcionarios del Ayuntamiento de Sarrión que han expresado su deseo de mantener el anonimato

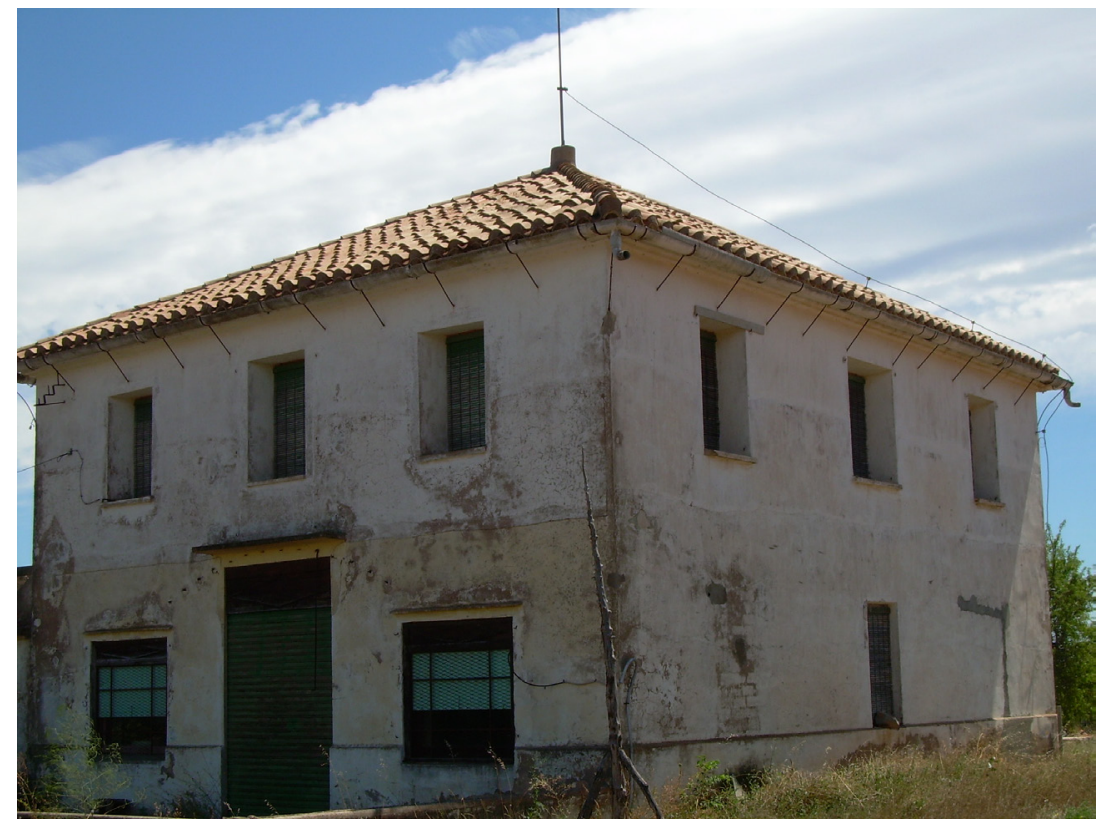


Situado ya en la provincia de Castellón, el Hospital de Viver tenía una gran importancia estratégica, ya que estaba situado cerca de Valencia y camino de Teruel. Este hospital fue instalado por la Cruz Roja en agosto de 1936, aunque le dedicamos un breve comentario por la gran cantidad de milicianos de la $\mathrm{CH}$ que fueron atendidos. La plantilla de este hospital estaba integrada por dos médicos, un practicante y cinco enfermeros, y su capacidad era de 40 camas. A partir de la lista de heridos que hemos localizado entre la documentación consultada podemos hacer una aproximación a la estructura del hospital. Se trata de los 16 heridos atendidos durante la semana del 16 al 22 de agosto de 1936 que presentaban heridas leves (contusiones, erosiones) y cuya estancia solía ser de un solo día, siendo la más larga de ocho días a causa de un cólico nefrítico ${ }^{62}$. Entre agosto y noviembre de 1936 fueron hospitalizados en Viver un total de 187 milicianos $^{63}$, aunque en general la ocupación del hospital durante este periodo fue muy baja ${ }^{64}$. El hecho de que en este centro sanitario se hospitalizara a tal cantidad de milicianos en cuatro meses pero que su ocupación fuera especialmente baja, junto con la levedad de los diagnósticos, nos permite afirmar que el Hospital de Viver fue concebido como un centro de corta estancia, donde eran atendidos milicianos heridos de levedad que rápidamente se reincorporaban a sus posiciones en el frente.

\section{CODA FINAL}

Durante la etapa revolucionaria de la Guerra Civil española, la Confederación Nacional del Trabajo en Valencia contó con un servicio propio de sanidad muy organizado, tanto en la retaguardia como en el frente de Teruel, donde operó su milicia. Durante el periodo de estudio el anarcosindicalismo valenciano ejerció la "acción directa» para resolver los problemas que venían afectando a la clase trabajadora desde la Segunda República. En primer lugar, pasó a gestionar los accidentes laborales con el objetivo de evitar fraudes por parte de las mutuas. Además, durante el periodo en el que la Dirección del Hospital Provincial de Valencia correspondió a la CNT tuvo lugar la expulsión del personal religioso y su sustitución por enfermeras profesionales. Sin embargo, la CNT valenciana también contempló la opción mutualista, apartando así el debate entre las dos corrientes y adoptando una postura muy pragmática ante una situación extraordinaria. Por otra parte, el estallido y posterior desarrollo de la Guerra Civil decantó la tendencia que se venía manteniendo desde principios de siglo XX en torno al debate de inclusión-exclusión de los trabajadores «intelectuales» en la CNT. El anarcosindicalismo valenciano optó por incluir a los profesionales sanitarios mostrando de nuevo un gran pragmatismo, ya que consideró que eran imprescindibles en una situación bélica. Ejemplos de esta inclusión son la relación de los servicios sanitarios de la CNT en el frente de Teruel con los mandos médicos del Ejército, y la composición del Comité directivo del Hospital Provincial durante el periodo de estudio. En definitiva, durante la Guerra Civil el anarquismo valenciano en el ámbito sanitario apartó todo tipo de debate motivo de división y se decantó por mecanismos de integración porque fue consciente que así lo requería la situación sanitaria derivada de la guerra. Resulta especialmente llamativo, así pues, que los anarquistas valencianos en el ámbito sanitario optaran primero por ganar la guerra y después completar la revolución, o sea, sustituir a los médicos desafectos. Esta interpretación estaba en las antípodas del ideario anarquista español en el ámbito socioeconómico: guerra y revolución a la vez.

El objetivo final de la política sanitaria del anarcosindicalismo valenciano era la colectivización de la asistencia sanitaria, para lo que la CNT aplicó criterios revolucionarios al ámbito sanitario, incluyendo numerosas incautaciones de recursos privados existentes. Además, el sindicato impulsó la construcción de una red sanitaria de base provincial que conjugó autonomía y coordinación. Respecto de las diferentes concepciones sanitarias existentes en el seno del Frente Popular, cabe señalar que en Valencia durante los primeros meses de la Guerra Civil, tales divergencias se manifestaron a través de la dicotomía entre guerra o revolución. Así, a diferencia de los anarquistas, los comunistas y republicanos valencianos consideraron que la sanidad no era un banco de pruebas al servicio de la revolución, sino que era fundamental para ganar la guerra. Esta postura se insinúa en el interés del PCE por controlar el mayor establecimiento sanitario del País Valenciano, esto es, el Hospital Provincial de Valencia.

Finalmente, la organización de los servicios sanitarios de la Columna de Hierro estuvo condicionada por las características del frente de guerra donde actuó. Efectivamente, el frente de Teruel durante la primera ofensiva republicana (agosto 1936-febrero de 1937) fue un frente de posiciones, muy diferente de otras campañas que se caracterizaron por grandes movimientos de tropas (por ejemplo, la segunda ofensiva sobre Teruel, desarrollada entre diciembre de 1937 y enero de 1938). Esta estabilidad bélica permitió la instalación de infraestructuras sanitarias muy estables. Además, el estudio de los partes médicos de los miembros hospitalizados de la Columna de Hierro nos ha proporcionado información muy valiosa sobre determinados aspectos no necesariamente sanitarios: la intensidad bélica del frente, la indisciplina, la falta de preparación y la improvisación. 


\section{NOTAS}

1 La política sanitaria de Montseny ha sido abordada por Barona y Bernabeu-Mestre (2007, pp. 33-47 y 2008, pp. 248-259). Además, la propia ministra pronunció una conferencia en Valencia el 6 de junio de 1937 donde relató su experiencia al frente del Ministerio de Sanidad y Asistencia Social. Esta fuente primaria continua siendo imprescindible para cualquier investigador de esta temática. Puede consultarse en Discurso de Montseny en el teatro Apolo. Fragua Social. 8-10 junio 1937. Hemeroteca Municipal de Valencia (H.M.V).

2 Para profundizar en esta cuestión es imprescindible analizar las propuestas del Pleno Nacional de Sindicatos Únicos de Sanidad y del Congreso Nacional de Sanidad, celebrados en Valencia en enero y marzo de 1937 respectivamente. Con este objetivo se pueden consultar las siguientes fuentes primarias: La organización sanitaria de la CNT. Del Pleno Nacional de Sanidad. Fragua Social. 9 de febrero de 1937; Los grandes comicios de la CNT. Primer Congreso Nacional de Sanidad. Fragua Social. 20 marzo 1937 a 4 abril 1937. Además, esta cuestión ha sido abordada en Jiménez-Lucena, 2004, pp. 158-159.

3 Los hospitales de sangre eran infraestructuras sanitarias habilitadas para acoger heridos y enfermos de guerra. Se instalaron en todo tipo de edificios confiscados (conventos, grupos escolares, clínicas particulares de médicos, chalets de la aristocracia...), así como en hospitales civiles adaptados a las necesidades de la guerra. Los hospitales de sangre se instalaban tanto en el frente como en la retaguardia.

4 Sobre la organización sanitaria de la Columna de Hierro tan solo encontramos alguna referencia más o menos escueta en obras que han estudiado la CNT o la columna en general. En este sentido consúltese Smyth, 1977, pp. 48-51; Mainar, 1998, pp. 72; Paz, 2001, p. 70; Amorós; 2009, p. 132.

5 Para ampliar información sobre el fracaso del golpe militar en Valencia, consúltese Mainar, 2006, vol. 2, pp. 17-27.

6 Decreto de 23 de diciembre de 1936 sobre la creación de los consejos provinciales, Gaceta de la República de 25 de diciembre de 1936 , no. 360, p. 1102 y siguientes.

7 Comité Sanitario Popular. Departamento de Hospitales. Fragua Social. 19 septiembre 1936; p. 4.

8 Orden del Ministerio de la Guerra de 23 de enero de 1937 sobre la militarización de los hospitales civiles, Gaceta de la República de 26 de enero de 1937, número 26, p. 510.

9 Para conocer la reorganización de la Sanidad Militar valenciana puede consultarse García Ferrandis, Munayco, 2011.

10 Para conocer la compleja red de asistencia sanitaria que se organizó en Valencia durante la guerra puede consultarse García Ferrandis, 2014a y 2014b.

11 Correspondencia. Incautación de las compañías de seguros. 29 agosto 1936. D.6.1 caja1. Archivo de la Diputación Provincial de Valencia (A.D.P.V.).

12 Correspondencia. Acta de incautación. 25 julio1936. D.6.1 c.1. A.D.P.V.
13 Correspondencia. Acta de incautación. 3 noviembre 1936. D.6.1 c.1. A.D.P.V.

14 Correspondencia. La responsabilidad de la clase médica ante el momento actual. [1937]. D.6.1 c.1. A.D.P.V. Se trata de un documento mecanografiado anónimo y sin datar. Por el contenido hemos inferido que se redactó a principios de 1937. Nuestra hipótesis es que el autor pudiera ser el propio Emilio Navarro Beltrán, o alguien de su entorno, en el contexto de preparación del Pleno Nacional de Sindicatos Únicos de Sanidad y del Congreso Nacional de Sanidad, celebrados ambos en Valencia en enero y marzo de 1937 respectivamente. Lo que sabemos con seguridad es que Navarro Beltrán asistió como consejero de Sanidad a ambos acontecimientos (Martí Boscà, Rey, 2010, p. 67).

15 Correspondencia. Proyecto de creación de la Delegación Sanitaria Regional del País Valenciano. [1936]. D.6.1 c.1. A.D.P.V.

16 Correspondencia. Representaciones de Distrito Provincial. [1936]. D.6.1 c.1. A.D.P.V.

17 Correspondencia. Socialización odontología. 18 septiembre 1936. D.6.1 c.1. A.D.P.V.

18 Correspondencia. Establecimiento de timbres sanitarios. 10 agosto 1936. D.6.1 c.1. A.D.P.V.

19 La obra que lleva a cabo el Control Sanitario de Valencia. Fragua Social. 22 octubre 1936; p. 13.

20 Fragua Social entre los hombres de ciencia. Fragua Social. 3 septiembre 1936; p. 3. El reportaje está ilustrado con imágenes de un aparato de onda corta, un radiólogo obteniendo una radiografía, un aparato de masaje muscular y un bisturí eléctrico.

21 Traslado de heridos a la Clínica Control de la CNT. 31 agosto 1936. Hospitales. D.6.1 caja 14. A.D.P.V.

22 Personal de la posta sanitaria de la Clínica de Control de la CNT. 17 de agosto de 1936. Hospitales. D.6.1 caja 14. A.D.P.V.

Las postas sanitarias de urgencia eran instalaciones donde se realizaban las primeras actuaciones sanitarias (control del dolor y de la hemorragia). En la ciudad de Valencia durante los primeros días de guerra se instalaron un total de 28 , tanto en edificios incautados (cines, plaza de toros, propiedades de la aristocracia, etc.), como en edificios civiles que existián antes de la guerra (casas de socorro, dispensarios, sedes de partidos políticos, etc). Al igual que los hospitales de sangre se podían habilitar en el frente y en la retaguardia. Para más información puede consultarse García Ferrandis, 2014.

23 Fragua Social entre los hombres de ciencia. Fragua Social. 3 septiembre 1936; p. 3

24 La obra que lleva a cabo el Control Sanitario de Valencia. Fragua Social. 22 octubre 1936; p. 13. Desgraciadamente la documentación consultada tan solo nos ha permitido caracterizar algunas de esas clínicas. Desconocemos si el resto llegó a materializarse o si la documentación referida ha desaparecido.

25 Nombramiento de un médico tocólogo para la Casa de Maternidad. 1 febrero 1937. D.6.1 c. 14. Hospitales. A.D.P.V. 
26 La obra que lleva a cabo el Control Sanitario de Valencia. Fragua Social. 22 octubre 1936; p. 13

27 Facturas. 20 mayo -30 mayo 1937. D.6.1 c. 12 . Maternidad. A.D.P.V.

28 Actas de las sesiones celebradas por el Consejo Provincial de Valencia (1937), Valencia, p. 120.

29 Hospital de Sangre de la CNT. 29 diciembre 1936. D.6.1 c. 14. Hospitales. A.D.P.V.

30 Sanatorio de Villa María. 3 diciembre 1936. D.6.1 c. 14. Hospitales. A.D.P.V.

31 Un orgullo de la CNT: la Mutua Confederal. Fragua Social. 5 octubre 1937; p. 4.

32 Actas de las reuniones de delegados de los servicios del Hospital Provincial y Manicomio. 19 diciembre 1936-26 marzo 1937. D.6.1 c.14. Hospitales. A.D.P.V.

33 Correspondencia. 5 agosto 1936. D.6.1 c.1. A.D.P.V.

34 Estadística del Hospital Provincial. 30 agosto 1936. D.2.6.4 c.12. A.D.P.V.

35 Proyecto de Reglamento de prestación de los diversos servicios del Hospital Provincial. [1937]. A.3.1.3 c. 20. A.D.P.V.

36 Certificados, oficios y relaciones de militares. 30 diciembre 1936. I-2.4 c.7 legajo 28. A.D.P.V

37 Actas de las sesiones celebradas por el Consejo Provincial de Valencia $(1937$,$) pp. 7-8.$

38 Decreto de 30 septiembre de 1937 sobre la remodelación de los consejos provinciales, Gaceta de la República de 1 octubre de 1937, no. 274, p. 22.

39 Actas de las sesiones celebradas por el Consejo Provincial de Valencia (1937), pp. 475-476.

40 Clausura del hospital de sangre de la CNT de Germanías. 10 octubre 1937. D.6.1 c. 14. Hospitales. A.D.P.V

41 Sanatorio de Villa María. 23 octubre 1937. D.6.1 c. 14. Hospitales. A.D.P.V.

42 Certificados, oficios y relaciones de militares. 17 diciembre 1936. I-2.4 c.7 legajo 28. A.D.P.V.

43 Informe de Navarro Beltrán. 30 diciembre 1936. D.6.1, c. 27. A.D.P.V.

44 Actas de las reuniones de delegados de los servicios del Hospital Provincial y Manicomio. 19 diciembre 1936-26 marzo 1937. D.6.1 c.14. Hospitales. A.D.P.V.

45 Correspondencia. La responsabilidad de la clase médica ante el momento actual. [1937]. D.6.1 c.1. A.D.P.V.

46 Equipos quirúrgicos de guerra. Mayo 1937. D.6.1 c. 27. A.D.P.V.
47 Certificados, oficios y relaciones de militares ingresados en el Hospital. 7 agosto 1937 . I-2.4 c. 8 legajo 28. A.D.P.V.

48 Decreto de 29 de septiembre de 1936 sobre la militarización de las milicias, Gaceta de Madrid de 30 de septiembre de 1936, no. 274, p. 2068

49 En esta ciudad aragonesa sí que había triunfado el golpe militar. La proximidad geográfica a Valencia suponía una clara amenaza para la ciudad, por lo que las autoridades revolucionarias se fijaron la conquista de Teruel como objetivo militar preferente. Para más información puede consultarse Mainar, 2006, pp. 37-48.

50 En el diario La Correspondencia de Valencia del 10 de agosto de 1936 puede observarse una imagen de esta ambulancia.

51 Informe de la visita realizada a los diversos servicios sanitarios de la Columna de Hierro. [Noviembre de 1936]. Servicios Sanitarios de la Columna de Hierro. Informe del estado de los Hospitales. D.6.1 c. 14. A.D.P.V.

52 Partes médicos. 29 septiembre 1936-11 febrero 1937. Partes de Teruel. Hospital de Cedrillas. D.6.1 c. 13. A.D.P.V.

53 Curiosamente, la relación se mantiene cuando el estudio se amplía a todas las fuerzas republicanas que participaron en las operaciones sobre Teruel entre el verano de 1936 y el invierno de 1937. Estos datos pueden consultarse en García Ferrandis, Munayco, 2010

54 Parte médico. 1 enero 1937. Partes de Teruel. Hospital de CedriIlas. D.6.1 c. 13. A.D.P.V

55 Nota del Control de Guerra de la Columna de Hierro. Fragua Social. 30 diciembre 1936; p. 2.

56 Toma de un chalet para instalar un hospital de sangre en Sarrión. 16 agosto 1936. Partes de Teruel. Hospital de Cedrillas. D.6.1 c. 13. A.D.P.V.

57 Visita al hospital instalado en Sarrión, por el personal del tren sanitario número 1. Fragua Social. 9 octubre 1936; p. 10. El reportaje está ilustrado con dos imágenes: el momento en que se radiografía a un herido, y el personal del tren sanitario número 1. También pueden encontrarse ilustraciones del tren y de su personal en La Correspondencia de Valencia de los días 18 y 19 de agosto y 4 de septiembre de 1936

58 Conviene aquí diferenciar entre Adolfo Rincón de Arellano Lobo (padre), médico militar republicano y Adolfo Rincón de Arellano García (hijo), falangista y alcalde de Valencia entre 1958 y 1969.

59 Telegramas de Rincón de Arellano Lobo al Comité Sanitario Popular anunciando la salida del tren con el número exacto de heridos y enfermos evacuados. 30 diciembre 1936. 1 enero 1937. 10 enero 1937. Partes de Teruel. Hospital de Cedrillas. D.6.1 c. 13. A.D.P.V.

60 En el frente de Teruel. La Correspondencia de Valencia. 4 septiembre 1936, p. 3.

61 Informe de la visita realizada a los diversos servicios sanitarios de la Columna de Hierro. [Noviembre de 1936]. Servicios Sanitarios de la Columna de Hierro. Informe del estado de los Hospitales. D.6.1 c. 14 . A.D.P.V. 
62 Hospital de Viver. Agosto 1936. D.6.1 c.6 . Hospitales de Sangre. A.D.P.V.

63 Carta del director del Hospital de Viver al Comité Sanitario Popular. 22 noviembre 1936. D.6.1 c.24. Hospital de Sangre de Viver. A.D.P.V.
64 Estadística de los asistidos y hospitalizados en el Hospital de Viver. Noviembre 1936. D.6.1 c.24. Hospital de Sangre de Viver. A.D.P.V.

\section{BIBLIOGRAFÍA}

Amorós, Miquel (2009), José Pellicer. El anarquista íntegro. Vida y obra del fundador de la heroica Columna de Hierro. Barcelona, Virus Editorial, p. 132

Arriaga, Mercedes; Cruzado, Ángeles; Estévez-Saá, Manuel; Torres, Katjia; Ramírez, Dolores (2007), Escritoras y Pensadoras Europeas, Sevilla, ArCiBel editores, pp. 23, 28-29.

Barona, Josep Lluís; Bernabeu-Mestre, Josep (2007), Ciencia y sanidad en la Valencia capital de la República, Valencia, Universitat de Valencia.

Barona, Josep Lluís; Bernabeu-Mestre, Josep (2008), La salud y el Estado. El movimiento sanitario internacional y la administración española (1851-1945), Valencia, Universitat de València.

Bernabeu-Mestre, Josep (2007), La salut pública que no va poder ser. José Estellés Salarich (1896-1990): una aportació valenciana a la sanitat espanyola comtemporània, Valencia, Consell Valencià de Cultura.

Cattini, Giovanni; Santacana, Carles (2002), "El anarquismo durante la Guerra Civil. Algunas reflexiones historiográficas", Ayer, 45 (1), pp. 197-219.

Fernández de Mendiola, Francisco (2007), Isaac Puente. El médico anarquista, Tafalla, Editorial Txalaparta, p. 222.

Fernández Soria, Juan (1996), Cultura y Libertad. La educación en las Juventudes Libertarias (1936-1939), Valencia, Universitat de Valencia.

García Ferrandis, Xavier; Munayco, Armando J. (2010), "La asistencia sanitaria en el frente de Teruel durante la primera campaña republicana (agosto de 1936-febrero de 1937)", Sanidad Militar. Revista de Sanidad de las Fuerzas Armadas de España, 66 (4), pp. 245-249.

García Ferrandis, Xavier; Munayco, Armando J. (2011), "La evolución de la Sanidad Militar en Valencia durante la Guerra Civil española (1936-1939)", Sanidad Militar. Revista de Sanidad de las Fuerzas Armadas de España, 67 (4), pp. 383-389.

García Ferrandis, Xavier (2012), "El Hospital Provincial de Valencia durante la Guerra Civil española (1936-1939)". En: Hinojosa, José (coord.), El Hospital General de Valencia (1512-2012), cinco siglos de vanguardia sanitaria, Valencia, Fundació Hospital Reial i General, pp. 364-381.
García Ferrandis, Xavier (2014a), "L’assistència sanitària a la ciutat de Valencia durant la Guerra Civil espanyola", Actes d'Història de la Ciència i de la Tècnica, 6, pp. 1-23, pp. 11-12.

García Ferrandis, Xavier (2014b), La reorganització de l'assistència sanitària a la ciutat de València durant la Guerra Civil espanyola (1936-1939), Valencia, Universitat de València (en prensa).

Hervàs Puyal, Carles (2004), Sanitat a Catalunya durant la República i la Guerra Civil, Tesis doctoral, Universitat Pompeu Fabra, Barcelona.

Jiménez-Lucena, Isabel (1998), “La cuestión del regeneracionismo sanitario y su debate durante la Segunda República: elementos de clase e ideología", Dynamis, 18, pp. 285-314.

Jiménez-Lucena, Isabel; Molero-Mesa, Jorge (2003), "Per una «sanitat proletària». L'organització sanitària obrera de la Confederació Nacional del Treball (CNT) a la Barcelona republicana (19351936)", Gimbernat, 39, pp. 211-221.

Jiménez-Lucena, Isabel (2004), “Asistencia sanitaria de, por y para los trabajadores: sanidad y anarquismo durante la Segunda República". In: Martí Boscà, José Vicente; Rey, Antonio (eds.), Actas del I Simposium Internacional Félix Martí Ibáñez: Medicina, Historia e Ideología, Valencia, Generalitat Valenciana, pp. 141-159.

Mainar, Eladi (1998), De milicians a soldats. Les columnes valencianes en la Guerra Civil espanyola (1936-1937), Valencia, Universitat de València, p. 72.

Mainar, Eladi (2006), “iTodos al frente!". En: Girona, Albert; Santacreu, José Miguel, (coords.), La Guerra Civil en la Comunidad Valenciana, Valencia, Editorial Prensa Valenciana, vol. 5, p. 37-48.

Mainar, Eladi (2006), "El fracaso del golpe de Estado". En: Girona, Albert; Santacreu, José Miguel, (coords.), La Guerra Civil en la Comunidad Valenciana, Valencia, Editorial Prensa Valenciana, vol. 2, pp. 17-27.

Martí, José Vicente (2006), "Revolución y sanidad en España, 1931-1939". En: Associació Cultural Alzina; Penalva, Clemente (coords.), La Rosa II/lustrada. Trobada sobre cultura anarquista i lliure pensament, Alicante, Publicacions de la Universitat d'Alacant, pp. 65-87. 
Martí Boscà, José Vicente; Rey, Antonio (2010), “Emilio Navarro Beltrán y Mercedes Maestre Martín: universidad, guerra y exilio". En: Facultades y grados. X Congreso Internacional de Historia de las universidades hispánicas, Valencia, Universitat de València, vol. II, pp. 59-72.

Massons, José María (1994), Historia de la Sanidad Militar Española, Barcelona, Ediciones Pomares-Corredor, p. 443.

Molero-Mesa, Jorge; Jiménez-Lucena, Isabel; Tabernero Holgado, Carlos (2013), "La "acción directa» y el mutualismo en el seno de la Confederación Nacional del Trabajo: la Obra Popular Antituberculosa de Cataluña", 1931-1932. En: VII Congreso de Historia Social. Mundo del trabajo asociacionismo en España. Collegia, gremios, mutuas, sindicatos... Madrid, Asociación de Historia Social, pp. 1-14.

Molero-Mesa, Jorge; Jiménez-Lucena, Isabel (2013), “"Brazo y cerebro»: Las dinámicas de inclusión-exclusión en torno a la profe- sión médica y el anarcosindicalismo español en el primer tercio del siglo XX", Dynamis, 33 (1), pp. 19-41

Paz, Abel (2001), Crónica de la Columna de Hierro, Barcelona, Virus Editorial, p. 70.

Smyth, Terence (1977), La CNT al País Valencià 1936-1937, Valencia, Eliseu Climent, pp. 48-51.

Stuart, Christie (2010), iNosotros los anarquistas! Un estudio de la Federación Anarquista Ibérica (FAI), 1927-1937, Valencia, Universitat de València.

Tabernero-Holgado, Carlos; Jiménez-Lucena, Isabel; Molero-Mesa, Jorge (2013), “Movimiento libertario y autogestión del conocimiento en la España del primer tercio del siglo XX: la sección "Preguntas y respuestas» (1930-1937) de la revista Estudios", Dynamis, 33 (1), pp. 43-67. 